\title{
The metastasis suppressor gene KISS-1 regulates osteosarcoma apoptosis and autophagy processes
}

\author{
YIRAN YIN ${ }^{1}$, LIAN TANG ${ }^{1}$ and LEI SHI $^{2}$ \\ Departments of ${ }^{1}$ Orthopedics and ${ }^{2}$ Gastroenterology, The Affiliated Hospital \\ of Southwest Medical University, Luzhou, Sichuan 646000, P.R. China
}

Received September 6, 2016; Accepted December 23, 2016

DOI: $10.3892 / \mathrm{mmr} .2017 .6109$

\begin{abstract}
The expression of the metastasis suppressor gene KISS-1 in osteosarcoma cells during apoptosis and autophagy was evaluated. MG-63 osteosarcoma cells were transfected with either KISS-1 overexpression or KISS-1 knockdown expression vector in vitro, and compared with cell lines transfected with empty vector. After 12, 24, 48 and $72 \mathrm{~h}$ of cell culture, the cell proliferation was examined. The MTT method was used to detect apoptosis by flow cytometry, and the mRNA levels of apoptosis and autophagy markers caspase-3, Bcl-2, Bax, LC3 and Beclin1 were assessed by RT-PCR. Our results showed that cells in the control and low expression group kept proliferating during the cell culture period of $72 \mathrm{~h}$, while the cells in the overexpression group progressively decreased in number. Also, the proliferation rate of the low expression group was significantly higher than that of the control group. The relative mRNA expression levels of caspase- 3 and Bax mRNA in the control and low expression group showed no change (the expression was lowest in the low expression group). Moreover, the mRNA level of Bcl-2 increased in both cell groups. The mRNA expression levels of caspase- 3 and Bax in the overexpression group were increased, and the level of Bcl-2 was reduced significantly. At the same time, the relative expression level of LC3 and Beclin1 mRNA in the control and low expression groups remained the same, and that of the overexpression group increased. The mRNA levels of LC3 and Beclin1 in the overexpression group were the highest, and that of the low expression group the lowest. The differences were statistically significant $(\mathrm{P}<0.05)$. Based on these results, we showed that KISS-1 inhibited the proliferation of osteosarcoma in vitro, probably by accelerating the processes of apoptosis and autophagy in the cells.
\end{abstract}

Correspondence to: Dr Lei Shi, Department of Gastroenterology, The Affiliated Hospital of Southwest Medical University, 25 Taiping Street, Luzhou, Sichuan 646000, P.R. China

E-mail: brs1841071684@163.com

Key words: KISS-1, osteosarcoma, proliferation, apoptosis, autophagy

\section{Introduction}

Osteosarcoma is one of the most common primary bone cancers among teenagers, it is prone to metastasis in its early stages, and its five-year survival rate is only $20-65 \%$ (1). Research shows that the occurrence and metastasis of osteosarcoma are closely related with the abnormal expression of the KISS-1/G proteincoupled receptor 54 (GPR54) gene system (2). The metastasis suppressor gene KISS-1 acts as a tumor suppressor gene in many tumors, such as in thyroid, pancreatic, bladder, ovarian and stomach cancer $(3,4)$, while it acts as a growth promoter in breast and liver cancer (5). In osteosarcoma cells cultured in vitro, the expression of the KISS-1 gene is negatively correlated to the cell proliferation and invasion (6), moreover, after KISS-1 transfection and overexpression, the proliferation and invasion of human osteosarcoma MG-63 and U-2OS cells decline. However, clinical studies have found that the patients with high expression of KISS-1 and GPR54 suffer a higher tumor metastasis rate and mortality $(7,8)$. This study was designed with those findings in mind, we used KISS-1 overexpression vector or siRNA to either highly express or knockdown expression of KISS-1 in the MG-63 osteosarcoma cell line in vitro, in order to analyze the mechanism of proliferation, apoptosis and autophagy of the tumor cells.

\section{Materials and methods}

Cell culture. MG-63 human osteosarcoma cells were brought from Shanghai Biotechnology Cell Experimental Center (Shanghai, China), and were cultured in the Dulbeco's modified Eagle's medium (DMEM) nutrient fluid, supplemented with $10 \%$ fetal bovine serum (FBS), $100 \mathrm{U} / \mathrm{ml}$ penicillin and streptomycin of $100 \mu \mathrm{g} / \mathrm{ml}$ final concentration (Beyotime Institute of Biotechnology, Jiangsu, China). The cells were placed in an incubator at $37^{\circ} \mathrm{C}$, with $5 \% \mathrm{CO}_{2}$ and saturated humidity. Cells were left to grow to confluency of more than $80 \%$, then adherent cells were digested with $0.25 \%$ trypsin and subcultured on a new flask. Every 2-3 days cells were subcultured, and maintained under the same conditions until ready for experiments. Cells for transfection experiments were selected when in the logarithmic phase.

Group division. We induced overexpression and knockdown expression of KISS-1 mRNA in cells of the osteosarcoma 
Table I. Sequences of the primers.

Forward primers

Reverse primers

\begin{tabular}{lll}
\hline Caspase-3 & 5'-GCCGTAGCAGCACGTAAATAA-3' & 5'-GTGCAGGGTCCGAGGT-3' \\
Bcl-2 & 5'-ACTACTTCTCCCGCCGCTAC-3' & 5'-GAAATCAAACAGAGGCCGCATG-3' \\
Bax & 5'-CCAGCACTTCACGCATCAG-3' & 5'-GCTGTCTAGCCAGAGTTTCAC-3' \\
LC3 & 5'-CTCGAGCTATGCCGTCCGAGAAGACCTTCA-3' & 5'-GAATTCTTACACAGCCATTGCTGTCCCGAA-3' \\
Beclin1 & 5'-CTGAGGAGCAGTGGACAAAGG-3' & 5'-GGAAGAGGGAAAGGACAGCAT-3' \\
Inter reference & 5'-TGCTTCACCACCTTCTTGA-3' & 5'-TCACCATCTTCCAGGAGC-3' \\
GAPDH & & \\
\hline
\end{tabular}

cell line MG-63 in vitro, and used the same type of cells as control by transfecting them with empty vector (GenePharma, Shanghai, China). The cDNA of KISS-1 from the osteosarcoma cells was amplified by RT-PCR, and the pcDNA3.1-vector (GenePharma) was used to make constructs for eukaryotic expression using standard molecular cloning techniques. Tranfections of the MG-63 cells with KISS-1 expression vector were done using Lipofectamine (both from GenePharma), and screened by G418 ( $1 \mathrm{mg} / \mathrm{ml})$. MG-63 cells with stable high expression of KISS-1 were subcultured. Additionally, a number of small interfering RNAs (siRNAs) were designed to knock down the KISS-1 expression in the MG-63 cells. The most effective siRNA segment giving the best silencing of KISS-1 expression was used in a eukaryotic expression vector pSUPER-KISS-1-siRNA, and transfected using Lipofectamine (both from GenePharma) into the cells (screened by G418 at $1 \mathrm{mg} / \mathrm{ml}$ ). The MG-63 cells with stable low expression of KISS-1 were subcultured and used in subsequent experiments. The control cell line was made by transfecting the empty pcDNA3.1-vector into MG-63 cells. KISS-1 expression was verified by RT-PCR method in all the resulting cell lines.

Research methods. After 12, 24, 48 and $72 \mathrm{~h}$ of transfections, the cell proliferation was examined for each cuture flask with the method of MTT. Apoptosis was detected by flow cytometry, the mRNA levels of caspase-3, Bcl-2 and Bax (apoptosis markers) as well as the mRNA levels of LC3 and Beclin1 were detected by RT-PCR.

MTT method. Cells were collected from the culture flasks when confluence reached $85 \%$ using trypsin digestion; $2,000 \mathrm{x} g$ of the cell culture medium containing resuspended cells were centrifuged for $15 \mathrm{~min}$, the cell pellet was saved and the supernatant discarded. Phosphate-buffered saline (PBS) was used to resuspend the pellet to a final concentration of $1 \times 10^{6} \mathrm{cells} / \mathrm{ml} ; 100 \mu \mathrm{l}$ of the resuspended cells were placed on each well of a 96 -well plate. The cells were incubated at $37^{\circ} \mathrm{C}$ with $5 \% \mathrm{CO}_{2}$ and saturated humidity for recovery and until attached. Then, $40 \mu \mathrm{l}$ of MTT solution was added to each well. The cells were further cultured in the incubator for $4 \mathrm{~h}$. In the following steps, the supernatants were removed, and $150 \mu \mathrm{l}$ of DMSO were added to each well, shaking for $10 \mathrm{~min}$. Finally, the absorbance (optical density, OD) at $490 \mathrm{~nm}$ wavelength was read in a microplate reader. The reference wavelength was $630 \mathrm{~nm}$. The process was repeated three times to average the results.
Flow cytometry. The cells were collected and washed in PBS. The binding buffer in the apoptosis assays kit (ZSGB-BIO, Beijing, China) was used to make a cell suspension, with the cell density adjusted to $1 \times 10^{6} / \mathrm{ml} ; 100 \mu \mathrm{l}$ of cell suspension were mixed with $5 \mu \mathrm{l}$ of Annexin V-FITC, and allowed to react for $5 \mathrm{~min}$ at room temperature in the dark. Then, $10 \mu \mathrm{l}$ of propidium iodide was added, the cells were left to react for $15 \mathrm{~min}$ at room temperature in the dark. Finally, $400 \mu \mathrm{l}$ of $1 \mathrm{X}$ binding buffer were added, before FACSCalibur flow cytometry (BD Biosciences, Franklin Lakes, NJ, USA) within $1 \mathrm{~h}$ to detect the cell apoptosis.

RT-PCR method. The traditional TRIzol method (KeyGene Biotech, Nanjing, China) was used to extract RNA, and its concentration and purity were detected with a UV spectrophotometer. cDNA was synthesized using a Sensiscript RT kit. Primers were synthesized by Takara Bio, Inc. (Otsu, Japan), the sequences are shown in Table I.

The reaction system consisted of $2.5 \mu \mathrm{l} 5 \mathrm{X}$ buffer $+1.5 \mu \mathrm{l}$ $\mathrm{MgCl}_{2}+0.5 \mu \mathrm{ldNTP}+1 \mu \mathrm{lGAP}-43$ with sense and antisense primers $+0.3 \mu 1 \mathrm{Taq}$ enzyme $+2 \mu \mathrm{l} \mathrm{cDNA}$ template and water to $25 \mu \mathrm{l}$. The reaction conditions were $95^{\circ} \mathrm{C}$ for $5 \mathrm{~min}, 95^{\circ} \mathrm{C}$ for $30 \mathrm{sec}, 62^{\circ} \mathrm{C}$ for $30 \mathrm{sec}, 72^{\circ} \mathrm{C}$ for $30 \mathrm{sec}$, and repeating the cycle 35 times, with a final at $72^{\circ} \mathrm{C}$ for $10 \mathrm{~min}$ extension. The dissociation curve was obtained and the $2^{-\Delta \Delta \mathrm{Ct}}$ method was used to calculate the relative expression of mRNA.

Statistical analysis. SPSS 20.0 software (IBM, Armonk, NY, USA) was adopted for statistical analyses. All quantitative data were expressed as mean \pm standard deviation (mean $\pm \mathrm{SD}$ ). The one-way analysis of variance (ANOVA) method was used for comparison among groups. The LSD-t method was used for comparison between two groups, and the repeated measure ANOVA was used for comparisons within one group. The differences were considered statistically significant at $\mathrm{P}<0.05$.

\section{Results}

Comparison of the cell proliferation rate. The cell proliferation rates were evaluated for $72 \mathrm{~h}$. The rates kept increasing for cells in the control and low expression groups, and decreased in the overexpression group. The rates in the low expression group were apparently higher than those in the control group. The differences had statistical significance $(\mathrm{P}<0.05)$ (Table II). 
Table II. Comparison of cell proliferation rate.

\begin{tabular}{lccccr}
\hline Groups & $12 \mathrm{~h}$ & $24 \mathrm{~h}$ & $48 \mathrm{~h}$ & $72 \mathrm{~h}$ & F-value \\
\hline Control & $0.64 \pm 0.15$ & $0.82 \pm 0.23$ & $1.13 \pm 0.34$ & $1.35 \pm 0.36$ & 6.532 \\
Overexpression & $0.52 \pm 0.12$ & $0.46 \pm 0.13$ & $0.38 \pm 0.09$ & $0.33 \pm 0.06$ & 6.421 \\
Low expression & $0.68 \pm 0.14$ & $0.91 \pm 0.18$ & $1.22 \pm 0.23$ & $1.46 \pm 0.29$ & 6.958 \\
F-value & 3.625 & 4.548 & 6.123 & 8.624 & 0.006 \\
P-value & 0.025 & 0.019 & 0.009 & $<0.001$ & $<0.001$ \\
\hline
\end{tabular}

Table III. Comparison of cell apoptosis rate (\%).

\begin{tabular}{lccccr}
\hline Groups & $12 \mathrm{~h}$ & $24 \mathrm{~h}$ & $48 \mathrm{~h}$ & $72 \mathrm{~h}$ & F-value \\
\hline Control & $15.6 \pm 4.5$ & $15.9 \pm 4.7$ & $16.3 \pm 3.8$ & $16.7 \pm 4.2$ & 1.236 \\
Overexpression & $24.6 \pm 6.6$ & $27.8 \pm 6.9$ & $35.4 \pm 8.2$ & $41.6 \pm 8.5$ & 5.628 \\
Low expression & $8.7 \pm 2.2$ & $9.2 \pm 2.3$ & $9.0 \pm 2.4$ & $9.4 \pm 2.1$ & 0.629 \\
F-value & 5.627 & 6.328 & 6.854 & 7.523 & 0.018 \\
P-value & 0.013 & 0.004 & $<0.001$ & $<0.001$ & 0.342 \\
\hline
\end{tabular}

Table IV. Comparison of the relative expression levels of apoptotic mRNA molecules.

\begin{tabular}{ccccc}
\hline Groups & Control group & Overexpression group & Low expression group & F-value \\
\hline Caspase-3 & & & & P-value \\
$12 \mathrm{~h}$ & $0.2341 \pm 0.0639$ & $0.3256 \pm 0.1124$ & $0.1532 \pm 0.0527$ & 3.625 \\
$24 \mathrm{~h}$ & $0.2143 \pm 0.0527$ & $0.3864 \pm 0.1325$ & $0.1426 \pm 0.0634$ & 4.123 \\
$48 \mathrm{~h}$ & $0.2056 \pm 0.0684$ & $0.4235 \pm 0.1527$ & $0.1352 \pm 0.0727$ & 4.432 \\
$72 \mathrm{~h}$ & $0.2135 \pm 0.0729$ & $0.4659 \pm 0.1632$ & $0.1428 \pm 0.0834$ & 4.865 \\
Bcl-2 & & & & 0.028 \\
$12 \mathrm{~h}$ & $0.5426 \pm 0.1532$ & $0.5213 \pm 0.1827$ & $0.6214 \pm 0.1532$ & 0.017 \\
$24 \mathrm{~h}$ & $0.5893 \pm 0.1426$ & $0.4629 \pm 0.2134$ & $0.6638 \pm 0.1627$ & 3.527 \\
$48 \mathrm{~h}$ & $0.6124 \pm 0.1827$ & $0.4123 \pm 0.1965$ & $0.7214 \pm 0.1824$ & 4.326 \\
$72 \mathrm{~h}$ & $0.6569 \pm 0.1932$ & $0.3526 \pm 0.1538$ & $0.7528 \pm 0.2131$ & 4.932 \\
Bax & & & & 0.033 \\
$12 \mathrm{~h}$ & $0.2135 \pm 0.0628$ & $0.4257 \pm 0.1824$ & 0.025 \\
$24 \mathrm{~h}$ & $0.2262 \pm 0.0762$ & $0.4826 \pm 0.2031$ & $0.1023 \pm 0.0624$ & 0.015 \\
$48 \mathrm{~h}$ & $0.2351 \pm 0.0839$ & $0.5328 \pm 0.2152$ & $0.1124 \pm 0.0537$ & 0.010 \\
$72 \mathrm{~h}$ & $0.2158 \pm 0.0528$ & $0.5925 \pm 0.2236$ & $0.0968 \pm 0.0162$ & 4.102 \\
\hline
\end{tabular}

Comparison of cell apoptosis rates. During the first $72 \mathrm{~h}$ after transfection, the cell apoptosis rates of the control and low expression groups did not change significantly, but that in the overexpression group increased. The rate of the overexpression group was significantly higher than that of the control group, and the low expression group had the lowest rates. The differences amongst groups had statistical significance $(\mathrm{P}<0.05)$ (Table III).

Comparison of the relative $m R N A$ expression levels of apoptotic molecules. With time, the relative expression levels of caspase- 3 and Bax mRNAs in the control and low expression groups remained the same, while the level of $\mathrm{Bcl}-2$ increased.
By contrast, in the overexpression group, the relative expression levels of caspase-3 and Bax mRNAs increased, and the level of Bcl-2 decreased. The levels of caspase- 3 and Bax in the overexpression group were higher than those in the control group, with the low expression group showing the lowest level. The level of Bcl-2 in the overexpression group was lower than that in the control group, and the low expression group had the highest level. The differences had statistical significance $(\mathrm{P}<0.05)$ (Table IV).

Comparison of the relative expression levels of $m R N A s$ of autophagy markers. With time, the relative expression levels of LC3 and Beclin1 mRNAs in the control and low expression 
Table V. Comparison of the relative expression levels of autophagy mRNA molecules.

\begin{tabular}{ccccc}
\hline Groups & Control group & Overexpression group & Low expression group & F-value \\
\hline LC3 & & & & P-value \\
$12 \mathrm{~h}$ & $0.1629 \pm 0.0862$ & $0.3341 \pm 0.1321$ & $0.0968 \pm 0.0132$ & 4.236 \\
$24 \mathrm{~h}$ & $0.1724 \pm 0.0764$ & $0.3935 \pm 0.1247$ & $0.1023 \pm 0.0235$ & 4.827 \\
$48 \mathrm{~h}$ & $0.1638 \pm 0.0912$ & $0.4452 \pm 0.1635$ & $0.0864 \pm 0.0321$ & 5.324 \\
$72 \mathrm{~h}$ & $0.1725 \pm 0.0834$ & $0.5124 \pm 0.1824$ & $0.0985 \pm 0.0245$ & 5.629 \\
Beclin1 & & & & 0.028 \\
$12 \mathrm{~h}$ & $0.1123 \pm 0.0737$ & $0.2659 \pm 0.1302$ & $0.0762 \pm 0.0326$ & 0.014 \\
$24 \mathrm{~h}$ & $0.1052 \pm 0.0629$ & $0.3124 \pm 0.1242$ & $0.0635 \pm 0.0257$ & 4.123 \\
$48 \mathrm{~h}$ & $0.1324 \pm 0.0538$ & $0.3762 \pm 0.1124$ & $0.0824 \pm 0.0241$ & 4.632 \\
$72 \mathrm{~h}$ & $0.1262 \pm 0.0624$ & $0.4213 \pm 0.1028$ & $0.0823 \pm 0.0169$ & 5.127 \\
\hline
\end{tabular}

group remained virtually unchange, while the level in the overexpression group increased. The expression in the overexpression group was higher than that of the control group, and the low expression group had the lowest levels. The differences had statistical significance $(\mathrm{P}<0.05)($ Table $\mathrm{V})$.

\section{Discussion}

KISS-1/GRP54 gene is mainly expressed in placental tissues, but can be also expressed in the central nervous system, testis, ovary, pancreas and small intestine (9). Kisspeptin is the translation product of KISS-1, it acts as the endogenous ligand of GPR54. The interaction between kisspeptin and GPR54 can activate the receptor, causing a cascade of effects through signaling pathways within the cells, which includes activation of phospholipase, calcium influx and regulation of collagenase activity, activating PI to release arachidonic acid, activating the MAPKs network and the extracellular signal-regulated protein kinases 1 and 2 (ERK1/ERK2) (10). The same interaction, however, can also inhibit the chemotactic activity of CXCR4, which plays an important role in promoting tumor metastasis (11). In addition, KISS-1 in cells can promote the release of $\mathrm{LH}$, and mediates the positive and negative feedback regulation of estrogen (12). Kisspeptin is related with the formation of the placenta and the invasion by trophoblast cells (13), a process similar to the invasion of a tumor.

Our results showed how the cell proliferation rates of the control and low expression group kept increasing with time, while that of the overexpression group was decreasing. Also, the rate of the low expression group was higher than that of the control group, and the overexpression group had the lowest rate. Based on this, it appears that KISS-1 can play a role as anti-oncogene. Along with the replication of transfected plasmid in the overexpression group, the levels of KISS-1 in that group were high, and the tumor proliferation activity was inhibited. By contrast, the low levels of expression of KISS-1 in the low expression group, lead to faster malignant proliferation. KISS-1 also displayed a role in apoptosis of the osteosarcoma cells. The cells with lower levels of expression (control and low expression groups) showed no difference in apoptosis rate with time, while cells overexpressing KISS-1 showed increasing apoptosis rates. The rate of apoptosis was highest in the KISS-1 overexpression group and lowest in the KISS-1 low expression group. KISS-1 in normal osteosarcoma cells had a relatively weak effect on promoting apoptosis. Caspase-3 is the 'key molecule' for apoptosis of the eukaryotic cells, drastically determining the level of apoptosis (14). Endogenetic-mitochondrion signaling apoptosis pathways play an important role in the apoptosis of tumor cells. The proteins, Bcl-2 and Bax have functions as anti-apoptosis and pro-apoptosis molecules, respectively. Their mutual antagonism influences the direction of apoptosis (15). In our study, the relative expression levels of caspase-3 and Bax mRNA in control group and low expression group remained relatively unchanged, and the level of Bcl-2 increased, while in the overexpression group, the relative expression levels of caspase- 3 and Bax mRNA increased, and the level of Bcl-2 decreased. Accordingly, the cells in the control and low expression group had low apoptosis activity, while the overexpression group cells displayed a high rate of apoptosis. Autophagy is different from apoptosis, and is characterized by typical autophagosomes formed inside the cells. Beclin1 is considered necessary for autophagy in the early stages. A complex formed with class III PI3K stimulates the formation of autophagosomes, Beclin1 guides related proteins to target the autophagosomes (16). LC3 is closely related to Beclin1 and is used as an autophagy marker in cells (17). During the time of cell culture, the relative expression levels of LC3 and Beclin1 mRNAs in the control and low expression groups had no change, but the level increased in the overexpression group, indicating that in this group the autophagy process was probably accelerated.

Based in our results, we conclude that KISS-1 can inhibit the proliferation of osteosarcoma in vitro by accelerating the processes of apoptosis and autophagy. KISS-1 is expected to become a new drug development target in the search for an effective treatment for osteosarcoma.

\section{References}

1. Yung KW, Yung TT and Chung CY: Principles of cancer staging. Asian Pac J Surg Oncol 1: 1-16, 2015.

2. Sanchez-Carbayo M, Belbin TJ, Scotlandi K, Prystowsky M, Baldini N, Childs $\mathrm{G}$ and Cordon-Cardo C: Expression profiling of osteosarcoma cells transfected with $M D R 1$ and $N E O$ genes: regulation of cell adhesion, apoptosis, and tumor suppression-related genes. Lab Invest 83: 507-517, 2003. 
3. Liang S and Yang ZL: Expression of KiSS-1 mRNA in pancreatic ductal adenocarcinoma and non-cancerous pancreatic tissues in SD rats. Zhong Nan Da Xue Xue Bao Yi Xue Ban 32: 109-113, 2007 (In Chinese)

4. Takeda T, Kikuchi E, Mikami S, Suzuki E, Matsumoto K, Miyajima A, Okada Y and Oya M: Prognostic role of KiSS-1 and possibility of therapeutic modality of metastin, the final peptide of the KiSS-1 gene, in urothelial carcinoma. Mol Cancer Ther 11: 853-863, 2012.

5. Papaoiconomou E, Lymperi M, Petraki C, Philippou A Msaouel P, Michalopoulou F, Kafiri G, Vassilakos G, Zografos G and Koutsilieris M: Kiss-1/GPR54 protein expression in breast cancer. Anticancer Res 34: 1401-1407, 2014.

6. Jabeen S, Qureshi MZ, Javed Z, Iqbal MJ, Ismail M and Farooqi AA: Kisspeptin mediated signaling in cancer. Curr Top Med Chem 16: 2471-2476, 2016.

7. Gründker C, Bauerschmitz G, Knapp J, Schmidt E, Olbrich T and Emons G: Inhibition of SDF-1/CXCR4-induced epithelial-mesenchymal transition by kisspeptin-10. Breast Cancer Res Treat 152: 41-50, 2015.

8. Wang FS, Chen H, Wu ZY and Lin JH: KISS1 expression in osteosarcoma: high in Chinese clinical cases, but lower in cell lines. Asian Pac J Cancer Prev 12: 3229-3234, 2011.

9. Song GQ and Zhao Y: Kisspeptin 10 inhibits the Warburg effect in breast cancer through the Smad signaling pathway: both in vitro and in vivo. Am J Transl Res 8: 188-195, 2016.

10. Castaño JP, Martínez-Fuentes AJ, Gutiérrez-Pascual E, Vaudry H, Tena-Sempere M and Malagón MM: Intracellular signaling pathways activated by kisspeptins through GPR54: do multiple signals underlie function diversity? Peptides 30 $10-15,2009$.
11. Navenot JM, Wang Z, Chopin M, Fujii N and Peiper SC: Kisspeptin-10-induced signaling of GPR54 negatively regulates chemotactic responses mediated by CXCR4: a potential mechanism for the metastasis suppressor activity of kisspeptins. Cancer Res 65: 10450-10456, 2005.

12. Radwańska P and Kosior-Korzecka U: Relationships between leptin, KiSS-1/GPR54 expression and TSH secretion from pituitary cells of pubertal ewes in vitro. Res Vet Sci 105: 180-187, 2016.

13. Soga T, Lim WL, Khoo AS and Parhar IS: Kisspeptin activates Ankrd 26 gene expression in migrating embryonic GnRH neurons. Front Endocrinol (Lausanne) 7: 15, 2016.

14. Li WH, Wu HJ, Li YX, Pan HG, Meng T and Wang X: MicroRNA-143 promotes apoptosis of osteosarcoma cells by caspase- 3 activation via targeting Bcl-2. Biomed Pharmacother 80: 8-15, 2016.

15. Lin BC, Huang D, Yu CQ, Mou Y, Liu YH, Zhang DW and Shi FJ: MicroRNA-184 modulates doxorubicin resistance in osteosarcoma cells by targeting BCL2L1. Med Sci Monit 22: 1761-1765, 2016.

16. Wu W, Li W, Zhou Y and Zhang C: Inhibition of beclin1 affects the chemotherapeutic sensitivity of osteosarcoma. Int J Clin Exp Pathol 7: 7114-7122, 2014.

17. Ma K, Zhang C, Huang MY, Li WY and Hu GQ: Cinobufagin induces autophagy-mediated cell death in human osteosarcoma U2OS cells through the ROS/JNK/p38 signaling pathway. Oncol Rep 36: 90-98, 2016. 